\title{
Blue Nevus Developing at a Combined Tetanus, Diphtheria, and Pertussis (Tdap) Vaccination Site: Case Report and Summary of Vaccine-Associated Cutaneous Lesions
}

\author{
Yoo Jung Kim ${ }^{1}$, Philip R. Cohen ${ }^{2}$ \\ 1. Dermatology, Stanford University, Stanford, USA 2. Dermatology, San Diego Family Dermatology, National City, \\ USA
}

Corresponding author: Yoo Jung Kim, yoojkim@stanford.edu

\begin{abstract}
Skin reaction may develop at the site of vaccine administration. A 54-year-old woman who developed a cellular blue nevus at the site of the combined tetanus, diphtheria, and acellular pertussis (Tdap) vaccine injection four years prior to presentation is described. In addition to blue nevus, other reactions at combined tetanus, diphtheria, and pertussis vaccine injection sites include abscess, deep reactive nodular infiltrates of mixed inflammation, and necrotizing granuloma. In conclusion, blue nevus can be added to the list of cutaneous events that can occur at Tdap vaccination sites.
\end{abstract}

Received 05/06/2019

Review began 05/06/2019 Review ended 06/11/2019 Published 06/25/2019

(๑) Copyright 2019

Kim et al. This is an open access article distributed under the terms of the Creative Commons Attribution License CC-BY 3.0., which permits unrestricted use, distribution, and reproduction in any medium, provided the original author and source are credited.
Categories: Dermatology

Keywords: blue, cutaneous, deltoid, diphtheria, nevus, papule, pertussis, tetanus, vaccination, vaccine

\section{Introduction}

Adverse cutaneous events can occur in vaccine injection sites [1]. These include inflammatory reactions and neoplasms. We describe a woman who developed a cellular blue nevus at the site of previous tetanus, diphtheria, and acellular pertussis (Tdap) injection. Cutaneous reactions to combined tetanus, diphtheria, and acellular pertussis vaccines and adverse skin reactions and neoplasms appearing in previous sites of vaccinations are also reviewed.

\section{Case Presentation}

A 54-year-old woman presented with a new lesion on her left arm. Four years prior to presentation, an acquaintance of the patient developed pertussis, which prompted the patient to seek immunization. The patient had not been vaccinated against pertussis in childhood. Based on the Center for Disease Control age recommendations, Tdap was administered on her left deltoid; the patient subsequently developed a new lesion over the previous site of the vaccine administration.

Cutaneous examination revealed a $5 \times 5 \mathrm{~mm}$ papule on her prior Tdap vaccination site (Figure 1). A punch biopsy was performed. Microscopic examination showed ovoid melanocytes in the dermis. Collagen was trapped between the melanocytes and the surrounding fibrous stroma. 


\section{Cureus}
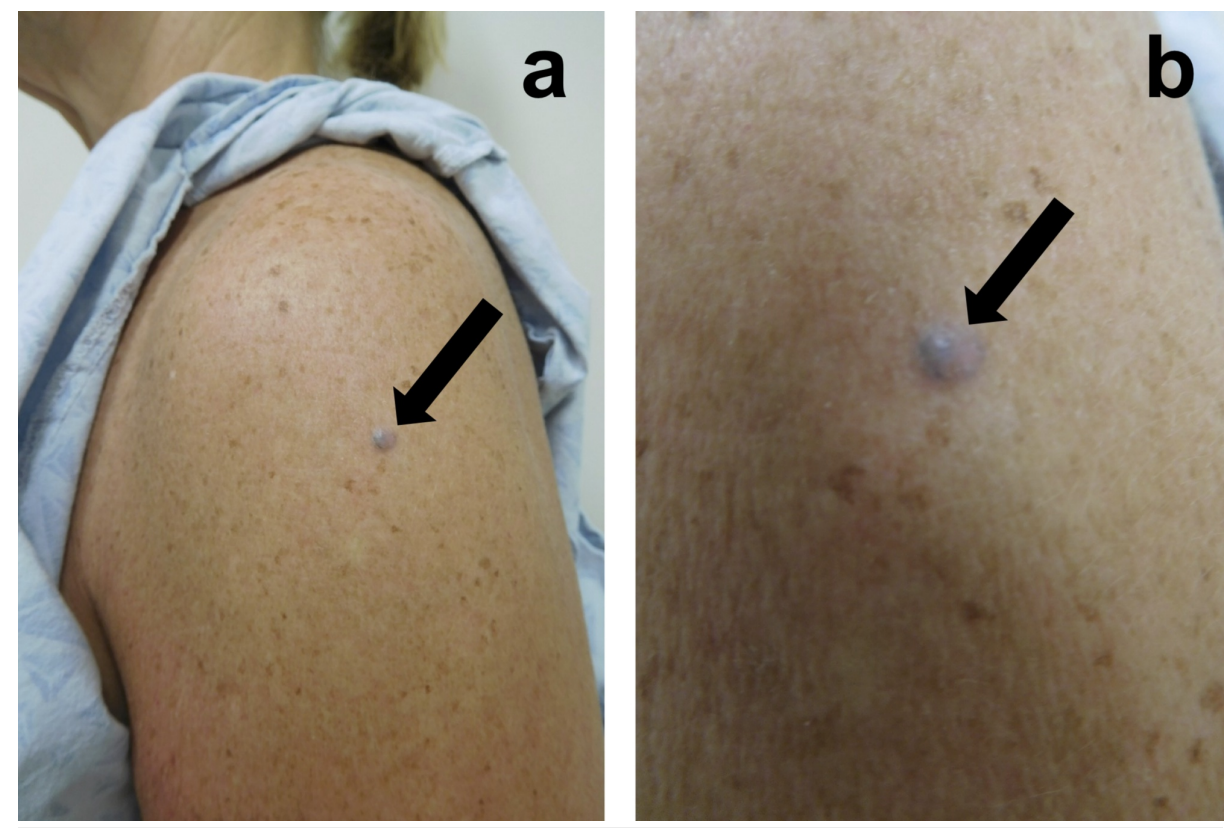

FIGURE 1: Cellular blue nevus appearing at the site of previous tetanus, diphtheria, and acellular pertussis (Tdap) vaccination

Distant (a) and closer (b) views of the deltoid area of the left arm of a 54-year-old woman showing a cellular blue nevus (black arrow) that developed at the site of a previous tetanus, diphtheria, and acellular pertussis (Tdap) vaccination that she received four years earlier.

Correlation of the clinical history, lesion morphology, and pathology established the diagnosis of a cellular blue nevus developing at the site of the Tdap vaccination. The residual lesion was excised. There has been no recurrence.

\section{Discussion}

The first vaccination against pertussis, also commonly called "whooping cough," was formulated using killed whole-cell Bordetella pertussis bacilli and licensed in 1914 [2]. Currently, there is no isolated vaccination for pertussis. Combination vaccines containing diphtheria toxoids, tetanus toxoids, and chemically-inactivated whole-cell pertussis were introduced as DTP in the 1940s; the acronym DTP was based on the first letter of each respective component. Subsequently, based on concerns regarding the adverse reactions to inactivated whole-cell pertussis, researchers developed an acellular vaccination for pertussis immunity; this vaccination came into wider use in the 1990s in the United States as the combined diphtheria, tetanus, and acellular pertussis vaccination (DTaP) [2-3].

The DTaP vaccination did not maintain adequate long-term humoral immunity against pertussis [4]. Therefore, a booster formulation of tetanus toxoid and smaller concentrations of the diphtheria toxoid and acellular pertussis received the approval from the Federal Drug Administration in 2005 as Tdap. Both DTaP and Tdap are currently in use. According to the United States Center for Disease Control, in children under seven years of age, DTaP is recommended, whereas for older children and for adults who have never been vaccinated, the Tdap is recommended [5].

Numerous cutaneous reactions have been observed at the sites of both live and attenuated vaccinations. These reactions include not only inflammatory reactions such as lichenoid and granulomatous dermatosis, but also neoplasms such as basal cell carcinoma, dermatofibrosarcoma protuberans, and squamous cell carcinoma (Table 1, Table 2) [1]. Skin-related reactions specific to diphtheria, tetanus, and pertussis vaccination include deep reactive nodular infiltrates of mixed inflammation, Mycobacterium tuberculosis abscess, and necrotizing granuloma (Table 3) [6-7]. The development of benign or malignant neoplasms at prior sites of vaccination may be coincidental.

\section{Cutaneous lesions}




\section{Cureus}

\begin{tabular}{|c|c|}
\hline Angiolymphoid hyperplasia with eosinophils & Tet \\
\hline Blistering & BCG \\
\hline Churg-Strauss vasculitis & НерВ \\
\hline DRNIMI & DTP \\
\hline Dermatitis, chronic & $\mathrm{Sp}$ \\
\hline Dermatofibroma & Sp \\
\hline Epithelial cyst & BCG \\
\hline Erythema & BCG, HepB, Pne, VZV \\
\hline Fixed drug eruption & BCG \\
\hline Foreign body granuloma (non-necrotizing) & BCG \\
\hline Granuloma annulare & BCG, HepB, Td, Tet \\
\hline Granuloma (delayed) & BCG \\
\hline Herpes simplex virus infection & Sp \\
\hline Indurated erythematous plaque (pseudoplymphoma) & Tet \\
\hline Inflammatory reaction, localized & Sp \\
\hline Itching granuloma & Pne, DTaP-IPV-Hib \\
\hline Isotopic response to patch testing & BCG \\
\hline Keloid & BCG, HepB, Sp \\
\hline Lichenoid dermatitis & Pne \\
\hline Lupus erythematosus (discoid) & Sp \\
\hline Lupus vulgaris (cutaneous tuberculosis) & BCG \\
\hline Lymphadenopathy (suppurative) & BCG \\
\hline Mastocytoma & НерВ \\
\hline Mycobacterium chelonae abscess & Tdap-IPV \\
\hline Mycobacterium tuberculosis abscess & DPT \\
\hline Myxedematous infiltration, diffuse & $\mathrm{Sp}$ \\
\hline Necrobiotic granuloma & НерВ \\
\hline Necrotizing granulomatous reaction & BCG, DTP \\
\hline Nevus sebaceous & $\mathrm{Sp}$ \\
\hline Nodules & НерВ \\
\hline Papular tuberculids & BCG \\
\hline PLAPR & НерВ \\
\hline Pigmentation & $\mathrm{Sp}$ \\
\hline Pilomatricoma & BCG \\
\hline Post scab lesions & $\mathrm{Sp}$ \\
\hline Progressive vaccinia & Sp \\
\hline Psoriasis & BCG, Flu \\
\hline Pyogenic infections & Sp \\
\hline Robust take $\mathrm{a}^{\mathrm{a}}$ & $\mathrm{Sp}$ \\
\hline Sarcoidosis (juvenile) & BCG \\
\hline
\end{tabular}




\section{Cureus}

Subcutaneous nodule (sterile abscess)

Subcutaneous nodule (pseudolymphoma)

Sweet's syndrome

Tufted angioma

Ulceration

Ulceration during Kawasaki disease

Vasculitis (ulcerating)

Zosteriform eruption
DTaP-IPV-Hib

ESM, HepB, VZV

BCG, Flu, Pne, Sp

BCG

BCG

BCG

BCG

VZV

\section{TABLE 1: Benign cutaneous lesions associated with vaccination sites}

BCG = Bacillus Calmette-Guerin vaccine; DRNIMI = Deep reactive nodular infiltrates of mixed inflammation; DTaP-IPV-Hib = Diphtheria, tetanus, pertussis, polio, Haemophilus influenzae Type B vaccine; DPT = Diphtheria, whole-cell pertussis, and tetanus vaccine; DTP = Diphtheria, tetanus, and whole-cell pertussis vaccine; ESM = Early summer meningitis vaccine; Flu = Influenza vaccine; HepB = Hepatitis B vaccine; PLAPR = Papulonodular lichenoid and pseudolymphomatous reaction; Pne = Pneumococcal vaccine; $\mathrm{Sp}=\mathrm{Smallpox}$ vaccine; $\mathrm{Td}=\mathrm{Tetanus}$ and diphtheria vaccine; Tdap-IPV = Tetanus, diphtheria, pertussis, and polio vaccine; Tet = Tetanus vaccine; VZV = Varicella-zoster virus vaccine

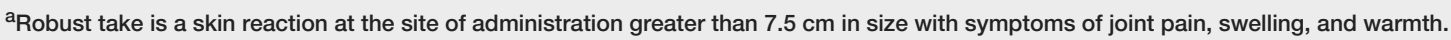

\section{Cutaneous lesions}

Basal cell carcinoma

Dermatofibrosarcoma protuberans

Fibrosarcoma

Keratoacanthoma

Malignant fibrous histiocytoma

Melanoma

Squamous cell carcinoma

\section{Vaccination}

BCG, Sp

Lsh, Sp, TPY, Travel immunization

Sp

Pne, Sp

Sp

Sp

BCG, Sp

\section{TABLE 2: Neoplasms associated with vaccination sites}

$B C G=$ Bacillus Calmette-Guerin vaccine; Lsh = Leishmaniasis vaccine; Pne = Pneumococcal vaccine; $\mathrm{Sp}=\mathrm{Smallpox}$ vaccine; $\mathrm{TPY}=$ Tetanus, plague, yellow fever vaccine 


\section{Cureus}

\begin{tabular}{|c|c|c|}
\hline Reaction & Vaccination & Reference \\
\hline Abscess (Mycobacterium tuberculosis) & $\mathrm{DPT}^{\mathrm{a}}$ & [6] \\
\hline Blue nevus & Tdap & CR \\
\hline DRNIMI & DTP & [7] \\
\hline Necrotizing granuloma & DTP & [7] \\
\hline
\end{tabular}

\section{TABLE 3: Combined tetanus, diphtheria, and pertussis vaccine site reactions}

CR = Current report; DRNIMI = Deep reactive nodular infiltrates of mixed inflammation; DPT = Diphtheria, whole-cell pertussis, and tetanus vaccine; DTP = Diphtheria, tetanus, and whole-cell pertussis vaccine; Tdap = Tetanus, diphtheria, and acellular pertussis vaccine

aThe cited reference refers to the combined diphtheria, whole-cell pertussis, and tetanus vaccination as "DPT," which is an alternative acronym for DTP.

Our patient developed a cellular blue nevus on the site of the injection after she received a Tdap vaccination [8]. To the best of our knowledge, she is the only person who has developed a vaccination site-related blue nevus. In addition, we are not aware of any other individuals developing a melanocytic lesion at the site of Tdap vaccination.

A postulated pathogenesis for the formation of a new cutaneous disease at a site of prior cutaneous insult has been attributed to the creation of an "immunocompromised district"-a localized site of immune destabilization in the skin leading to increased risk of developing dermatoses [9]. Through this potential mechanism, vaccination administration may allow the site to be more prone to developing a wide array of skin conditions. The appearance of our patient's cellular blue nevus following localized skin trauma from the vaccination may be the etiology of this phenomenon.

The administration of vaccinations is extremely common. The development of cutaneous adverse reactions at the site of vaccination is a rare occurrence. Although the rate for cutaneous adverse reactions at the vaccination sites remains to be established, the estimated rate would be very low based on the published literature of these events.

\section{Conclusions}

Adverse events may occur in local vaccination sites. Our patient developed a cellular blue nevus at the site of the Tdap vaccine administration. The development of a melanocytic nevus at the site of Tdap vaccination has not been previously described as a post-vaccination sequela. We suggest that this vaccination siterelated tumor may have resulted from the creation of a local immunocompromised district in the skin following Tdap vaccination.

\section{Additional Information}

\section{Disclosures}

Human subjects: Consent was obtained by all participants in this study. Conflicts of interest: In compliance with the ICMJE uniform disclosure form, all authors declare the following: Payment/services info: All authors have declared that no financial support was received from any organization for the submitted work. Financial relationships: All authors have declared that they have no financial relationships at present or within the previous three years with any organizations that might have an interest in the submitted work. Other relationships: All authors have declared that there are no other relationships or activities that could appear to have influenced the submitted work.

\section{References}

1. Cohen PR: Injection site lichenoid dermatitis following pneumococcal vaccination: report and review of cutaneous conditions occurring at vaccination sites. Dermatol Ther. 2016, 6:287-298. 10.1007/s13555-0160105-X

2. Klein NP: Licensed pertussis vaccines in the United States. History and current state . Hum Vaccin Immunother. 2014, 10:2684-2690. 10.4161/hv.29576

3. Kuchar E, Karlikowska-Skwarnik M, Han S, Nitsch-Osuch A: Pertussis: history of the disease and current prevention failure. Adv Exp Med Biol. 2016, 934:77-82. 10.1007/5584_2016_21

4. Olin P, Gustafsson L, Barreto L, et al.: Declining pertussis incidence in Sweden following the introduction of acellular pertussis vaccine. Vaccine. 2003, 21:2015-2021. 10.1016/S0264-410X(02)00777-6

5. Liang JL, Tiwari T, Moro P, et al.: Prevention of pertussis, tetanus, and diphtheria with vaccines in the 


\section{Cureus}

United States: recommendations of the Advisory Committee on Immunization Practices (ACIP). MMWR Recomm Rep. 2018, 62:1-44. 10.15585/mmwr.rr6702a1

6. Dixit R, Dixit K, Patil CB, Pawar KS: Injection site abscess due to Mycobacterium tuberculosis following DPT vaccination. Indian J Tuberc. 2014, 61:246-249.

7. Miliauskas JR, Mukherjee T, Dixon B: Postimmunization (vaccination) injection-site reactions. A report of four cases and review of the literature. Am J Surg Pathol. 1993, 17:516-524.

8. Zembowicz A, Phadke PA: Blue nevi and variants: an update. Arch Pathol Lab Med. 2011, 135:327-336.

9. Ruocco V, Brunetti G, Puca RV, Ruocco E: The immunocompromised district: a unifying concept for lymphoedematous, herpes-infected and otherwise damaged sites. J Eur Acad Dermatol Venereol. 2009, 23:1364-1373. 10.1111/j.1468-3083.2009.03345.x 